\title{
Loops Forming Networks
}

National Cancer Institute

\section{Source}

National Cancer Institute. Loops Forming Networks. NCI Thesaurus. Code C111026.

A microscopic finding indicating the presence or absence of loops forming networks in uveal melanoma. 